\title{
HONORIS CAUSA: \\ ELOGIO DE AGUSTÍN ESCOLANO BENITO
}

DOI: http://dx.doi.org/10.1590/2236-3459/57715

\section{HONORIS CAUSA: PRAISE OF AGUSTÍN ESCOLANO BENITO}

\author{
Justino Pereira de Magalhães \\ Instituto da Educação da Universidade de Lisboa, Portugal.
}

\section{$\cos 80$}

Magnífico reitor da Universidade de Lisboa.

Representantes dos magníficos reitores de outras universidades.

Exmo. senhor professor António Nóvoa, Reitor Honorário da Universidade de Lisboa.

Exmo. senhor director do Instituto de Educação da Universidade de Lisboa.

Exmos. senhores directores e Presidentes de outras Faculdades e Institutos.

Exmas. autoridades políticas e civis.

Exmos. senhores magistrados.

Exmo. Ssnhor Embaixador de Espanha.

Exmos. senhores professores das universidades portuguesas, espanholas, brasileiras.

Exmo. senhor professor Sérgio Niza, Doutor Honoris Causa por esta Universidade e a quem endereço uma saudação muito especial.

Prezado senhor professor doutor Agustín Escolano Benito.

Minhas senhoras e meus senhores.

Caríssimos estudantes.

O Instituto de Educação da Universidade de Lisboa, sempre empenhado em trazer a Educação para o debate académico e institucional, propôs ao Magnífico Reitor desta Universidade a atribuição do grau de Doutor Honoris Causa a Agustín Escolano Benito. Esta proposta foi aprovada pelo Senado Universitário na reunião de 14 de outubro de 2014. 
1. Agustín Escolano Benito é director, desde 2006, do Centro Internacional de la Cultura Escolar - Ceince -, com sede em Berlanga do Douro, e é director, desde 2011, da Cátedra Memória e Património da Educação, da Universidade Europeia Miguel Cervantes.

Nascido em 1941, em Berlanga do Douro, Soria, Espanha, onde reside, Agustín Escolano Benito licenciou-se em Filosofia e Letras, Secção de Pedagogia, na Universidade Complutense de Madrid, em 1964. Obteve doutoramento, pela Universidade de Madrid, em 1972. Foi professor de instrução secundária e inspector do ensino primário em Santander e Barcelona. Entre 1964 e 1975, foi sucessivamente professor na Universidade Complutense de Madrid, na Universidade de Oviedo e na Universidade Autónoma de Barcelona. De 1976 a 1992, foi catedrático de História da Educação, na Universidade de Salamanca, onde foi director do Instituto de Ciências da Educação. Entre 1992 e 2010, foi catedrático de Teoria e História da Educação, na Universidade de Valladolid.

É autor de mais de duas dezenas de livros e de três centenas de artigos e capítulos de livro em publicações espanholas e em publicações estrangeiras. Está traduzido em francês, inglês, português, italiano. É editor e co-autor de duas dezenas de obras que contaram com a colaboração dos mais prestigiados investigadores. Em consentâneo com as Ciências da Educação, foi autor de manuais escolares de educação social, de educação cívica, de ensino da história.

Como académico e homem de ciência, Agustín Escolano deu dignidade magistral às cátedras que ocupou. Dirigiu seminários e foi director de teses doutorais de investigadores espanhóis e de investigadores oriundos de diferentes países, entre os quais Portugal. As largas dezenas de teses que orientou ou que estão em curso incidem fundamentalmente sobre a realidade histórico-pedagógica espanhola, mas também sobre a realidade ibero-americana, em sentido amplo e de modo comparado.

Tem sido professor visitante de universidades americanas e europeias, entre as quais a Universidade de Lisboa, onde tem colaborado regularmente, como supervisor e consultor de projectos e redes de investigação, bem assim como na orientação de seminários doutorais. Está associado a meia centena de projectos de investigação, que criou e dirigiu ou nos quais colaborou e colabora.

2. O nome de Agustín Escolano é inseparável da renovação da História da Educação espanhola, desde a abertura democrática da Espanha pós-franquista. Fundou revistas da especialidade em História da Educação: a revista Studia Paedagogica de que foi editor; a revista interuniversitária Historia de la Educación, de que foi director. Fundou e dirigiu a Colecção Ciências da Educação da Universidade de Salamanca. Foi director da colecção Memória e Crítica da Educação, monografias e manuais universitários, da Editorial Biblioteca Nueva, Madrid.

Entre as principais iniciativas, pessoais e conjuntas com outros professores e investigadores, destaco a criação da Sociedade Espanhola de História da Educação Sedhe -, de que foi presidente. Desde 1998 preside à Sociedade Castellano-Leonesa de História da Educação e desde 2003 preside também à Associação Schola Nostra. Estes contributos são decisivos para o intercâmbio do conhecimento, a produção e o debate científico nas mais distintas latitudes. 
Agustín Escolano integra redes internacionais de investigação, no âmbito das quais tem vindo a renovar o conhecimento científico dos mundos Mediterrânico e hispanoamericano. Visando o estudo da instituição escolar na Europa de Sul, promoveu a fundação da Sodalitas Pro Investigatione Comparata Adhaesa Educationi - Spicae -, que integrou investigadores italianos, espanhóis e portugueses. Foi membro do Comité Executivo do International Standing Conference for the History of Education - Ische. Foi Consultor da Unesco, no âmbito disciplinar da educação superior nos países mediterrânicos.

Pela orientação de teses, das publicações, dos numerosos e inovadores projectos, Agustín Escolano tem sabido contribuir, de forma única, para a consolidação de uma Memória Histórica da Educação, nos períodos Moderno e Contemporâneo, em Espanha, na Europa, no espaço ibero-americano.

A obra de Agustín Escolano inclui, como já referi, temas de cidadania histórica, com particular destaque para a preservação e a divulgação do património artístico e cultural. Humanista e homem de contemplação, tem ainda encontrado tempo para reconstituir o universo espiritual de Castela, inventariando os locais de meditação e escrevendo roteiros; dissertando sobre o património arqueológico, oral e edificado; elaborando memórias e guias de viagem pelos ermitérios e por paisagens histórico-culturais de Berlanga e Soria.

3. Profundo conhecedor da história ibérica, Agustín Escolano é animador incansável da cooperação científica entre Espanha e Portugal pelo intercâmbio entre a Sociedade Espanhola de História da Educação e a Secção Portuguesa de História da Educação, bem como no contexto do Douro Internacional e de projectos bilaterais e interinstitucionais. Mantém participação regular com investigadores e universidades portuguesas, particularmente com o Instituto de Educação da Universidade de Lisboa, onde, reitere-se, tem estado frequentemente em reuniões de trabalho, eventos científicos, colóquios, seminários.

Em 2006, com impulso da Associação Schola Nostra, que congrega professores de diferentes graus de ensino, e com apoio da Fundação Germán Sánchez Ruipérez e da Consejeria de Educación da Junta de Castilla, fundou o Centro Internacional de Cultura Escolar - Ceince. Com incidência na área de memória e património da educação; na área de manualística; na área de cultura escolar e sociedade do conhecimento, o Ceince constitui uma referência mundial, reunindo materiais escolares e educativos dos diversos quadrantes geográficos e culturais e recebendo investigadores de todo o mundo. É museu, hemeroteca e digitalia. Neste museu-laboratório realizam-se encontros científicos, seminários, simpósios, missões de investigação. Ali estão conservados e disponíveis mais de 50 mil manuais e escritos escolares em praticamente todas as línguas. Este centro de memória e de investigação tornou-se já lugar de peregrinação para historiadores e investigadores de Ciências da Educação, e das Ciências Sociais e Humanas.

Individualidade de projecção internacional, Agustín Escolano distingue-se pelo contributo que tem sabido dar às Ciências da Educação, muito particularmente à História e Teoria da Educação; pela capacidade de iniciativa e de mobilização das comunidades científica e académica; pela valorização da Educação e das Ciências da Educação no 
quadro das Humanidades e no desenvolvimento da Sociedade Contemporânea. A obra escrita de Agustín Escolano é de abrangência interdisciplinar no campo da Educação, mas ganha coerência e sentido na afirmação da Educação como meio de formação, cidadania, ciência, humanitude.

A docência, bem como a obra científica de Agustín Escolano, tem como eixo uma pedagogia humanista. É educador e pedagogo por vocação, missão que assume como mestre e mobilizador de vontades, saberes, políticas. $O$ sentido magistral está presente, incentivando, abrindo caminho, inventando projectos, criando e dinamizando redes e grupos de trabalho.

Agustín Escolano tem feito escola, no sentido mais profundo do termo, e tem feito da escola e, com mais propriedade, da cultura escolar, o tema de eleição. Desenvolveu a etno-história da escola, no quadro de uma revisitação hermenêutica da cultura escolar. Trabalhou a materialidade, a manualística, a imagética, os espaços, os métodos, a leitura e o livro escolar. Para Agustín Escolano os discursos pedagógicos constituem o eixo de interdisciplinaridade e de confluência temática, mas é a partir de uma recolha e da abordagem criteriosa da materialidade e das práticas - designadamente a arte do professor, a produção dos alunos, o tempo escolar, o curriculum -, que desenvolve estudos histórico-comparados e em rede. Discute a relação entre escola e modernização da sociedade. A cultura escolar e a materialidade escolar merecem-lhe a aplicação de três conceitos: manualística, economia escriturária, memorabilia. No campo da manualística, os seus estudos são referência teórica e integrou o grupo que lançou o projecto Manes e posteriormente a Rede Manes, que detém um banco de dados em que estão indexados manuais escolares de Espanha, Portugal, Bélgica e países da América do Sul. A Rede Manes está actualmente agregada ao Ceince.

4. Antes de concluir, permitam-me que faça uma pequena deriva. Vai para mais de dois séculos que Jean-Jacques Rousseau lançou uma terrível inquietação sobre a educação e, muito particularmente, sobre a escola. O legado de Rousseau continua, a meu ver paradoxalmente, a dividir os pedagogistas, entre defensores da escola e detractores da escola, no que reporta à natureza e à sua função, seja como sede do conhecimento, seja como matriz de soberania social. Mas foi o mesmo Jean-Jacques Rousseau que, no Livro I de Émile, nos deu a melhor definição de cidadania e de compromisso colectivo, ao narrar, de forma breve, o episódio de um cidadão de Esparta. Este cidadão dirigiu-se à praça, na esperança de vir a ser um dos trezentos magistrados eleitos. Não foi escolhido. Todavia, recolheu-se a casa com júbilo e pacificado do espírito, dizendo a si próprio que havia afinal, na sua cidade, trezentos cidadãos melhores do que ele.

Confiada a oficiais cuja linha de horizonte é, não raro, demasiado curta perante a longevidade e o sublime do humano, a humanidade continua por cumprir. A sociedade busca referências sólidas de sabedoria, ética e vontade. A academia faz parte dessa busca e a educação é o caminho sólido. Hoje, ainda que em número escasso face aos múltiplos desafios, há mestres. Assim os saibamos reconhecer e distinguir.

Agustín Escolano é um humanista que soube trazer as Ciências da Educação para o mundo universitário e repor a Educação entre os desafios da sociedade contemporânea. Senhor de uma excepcional capacidade de inovação científica, soube aglutinar esforços e ideias, construindo um tecido académico entre um e outro lado do Atlântico, promovendo 
encontros, disseminando ideias, coordenando projectos. Abriu novos territórios de investigação histórico-educativa. Contribuiu de forma exemplar para arrancar da rotina e da mediocridade os estudos de História da Educação, modernizando-os e europeizandoos. Criou escola.

A personalidade de distinto prestígio científico e académico que é Agustín Escolano, e de que aqui tracei brevíssima apresentação, tem sido certificada pelas dezenas de testemunhos que temos vindo a receber no Instituto de Educação, enviados por reitores, investigadores, professores e por membros de sociedades científicas europeias e americanas.

Magnífico Reitor da Universidade de Lisboa e excelentíssimos membros desta Assembleia, antes de evocar a V/ ilustre e avisada soberania, permitam-me que termine afirmando: como mestre, como referência ética, como cidadão do mundo, que sabe acolher e conduzir os destinos individuais e colectivos, Agustín Escolano Benito deve, inequivocamente, fazer parte dos eleitos.

Tenho dito.

Lisboa, 23 de abril de 2015.

Justino Pereira de Magalhães.

JUSTINO PEREIRA DE MAGALHÃES é professor catedrático na Universidade de Lisboa.

Endereço: Unidade de Investigação e Desenvolvimento em Educação e Formação Alameda da Universidade - Lisboa - 1649-013 - Portugal.

E-mail: justinomagalhaes@ie.ul.pt.

Recebido em 26 de julho de 2015.

Aceito em 20 de agosto de 2015. 